\title{
Scarabs, Scaraboids, Seals, Seal Impressions, and Knotted Cords
}

\author{
Emily Teeter
}

1 Scarabs, Scaraboids, and Seals Catalogue

The $\mathrm{N} 2000$ cemetery yielded only a few scarabs and seals: four scarabs or scaraboids, a button seal, and a hemi-cylindrical seal. ${ }^{1}$ Most were found singly, although two were recovered from $\mathrm{N}_{71-71} \mathrm{~b}$. The paucity of seals contrasts with sites such as Qau, Badari, and Hememieh where at least 229 button and scarabs were recovered (Brunton 1927, 58).

Explanation of the Scarabs, Scaraboids, and Seals Catalogue:

The finds' description of context below is taken from the Catalogue of Tombs. The photograph numbers reflect the original excavator's numbering system.

Museum Registration: Name and museum number of object.

Material: Copper alloy, faience, glazed material, glazed steatite, steatite, textile. Measurements: Length, width, depth. Also, weight.

Color: Blue-green, brown, green.

Date: Dynasties 7-11.

1 Apparently, there were a few more scarabs from the 2000 cemetery, including PAHMA 6-14372 that was strung on beads from N 2071a-b and MFA 21.981, 21.982 (both from N 434B). See Reisner (1932, 115, fig. 50:19, 116, section 2v) for a "faience lion-seal" (PAHMA 6-14381) from $\mathrm{N} 2072$ that is treated in the chapter Beads, Pendants, and the Like. 


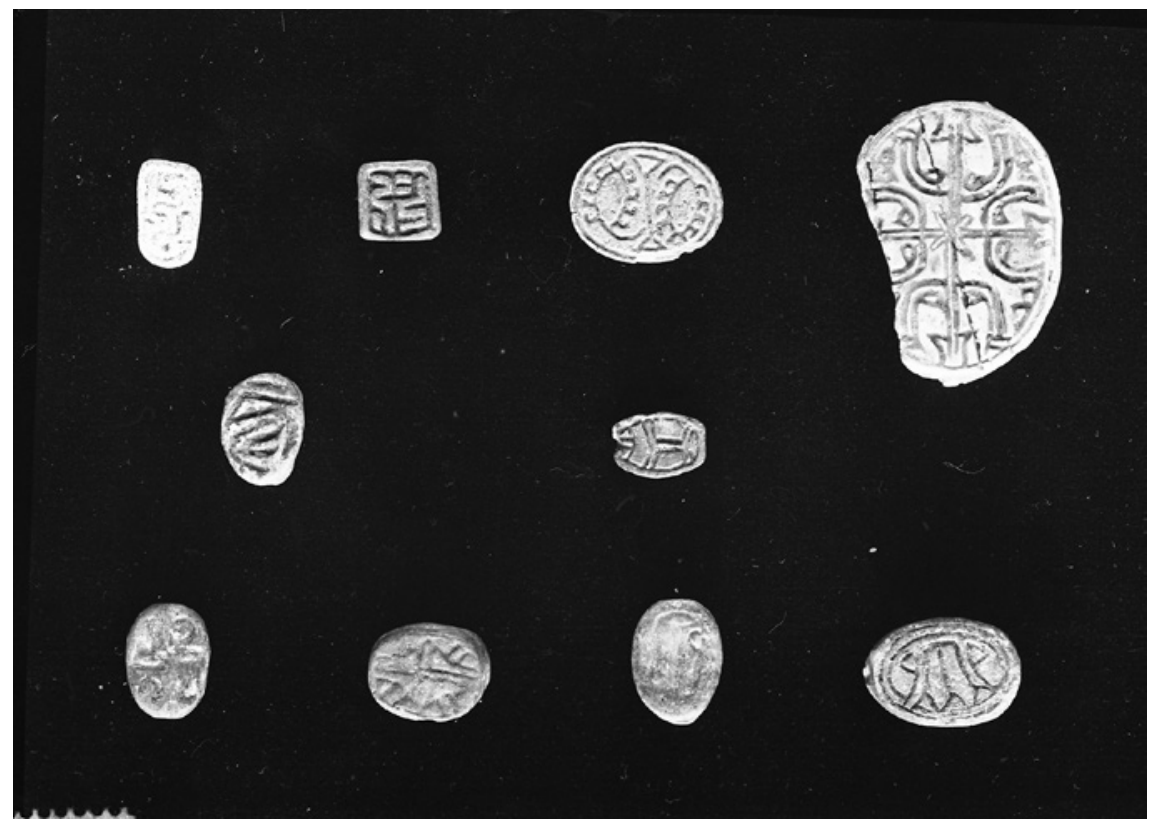

FIGURE 4.1 Seals and scarabs 1st row: 6-14381 (N 2072), 6-14328 (N 2034), 6-14348 (N 2048), 6-14383 (N 2075); 2nd row: 6-14374, 6-14372 (N 2071); 3rd row: 6-14367 (all 4 objects; $\mathrm{N}$ 2071) (NED-C-8285)

N 2034 Map E4; photo C o993, B 7129

In large chamber, small faience plaque (PAн MA 6-14328). (See note, below.)

(1) РАнма 6-14328 Hemi-cylinder seal (Figs. 4.1, 4.2)

Material: Steatite.

Measurements: L $0.74 \times \mathrm{W} 0.725 \times \mathrm{D} 0.40 \mathrm{~cm}$.

Weight: $0.02 \mathrm{~g}$.

Color: Green.

Date: First Intermediate Period, Dynasties 7-11.

Small square seal-like amulet with a hemi-cylinder-shaped back. The handle on the back bears a raised floral-like pattern. The back of the seal below the handle has a raised rim, so when the seal is seen from the top, the floral pattern appears to be enclosed in the square frame. ${ }^{2}$ The hemi-cylinder is pierced.

2 The pattern on the back does not look like the drawing in Reisner (1932, 114, fig. 49.5) (reproduced by Wiese 1996, pl. 6o, no. 1227), where it is shown as being a crosshatched pattern, whereas the pattern looks floral. 
The underside has a meandering line pattern or maze/labyrinth pattern in a square frame. The object is covered with green glaze.

Note on provenience: There is confusion in the records about the provenience of this seal. According to one set of Hearst Museum records, it is from $\mathrm{N} 2032^{2}$ (tomb of Pepi-Iam, a hi3ty-c and seal bearer of the King of Lower Egypt), while according to the older set of Hearst Museum records and the original (and more accurate) documentation, it is from $\mathrm{N} 2034$.

Note on date: The date is based on the provenience, which is confirmed by the pattern that is seen on other scarabs/seals of the First Intermediate Period. Brunton $(1927,57)$ dates the square hemi-cylinders to Dynasties $7-8$. Haynes and Markowitz (1991, no. 7) comment "these linear patterns are characteristic of First Intermediate design amulets and scarabs."

This type of hemi-cylinder occurs in Dynasty 6 and disappears in Dynasty 11 (Newberry 1906, 57-58; Reisner 1932, 119).

This form of seal is referred to by various names, most commonly a "hemicylinder" (Newberry 1906, 56-61; Brunton 1927, 55-56), "halbzylinder" (Wiese 1996, 55-56, 59-61) or "cylinder + plate-seal" (Reisner 1932, 115, 118, 119). It has been associated with the earliest stamp seals, although it is unclear if the first stamp seals were in this form or buttons (Reisner 1932, 119). Reisner (1932, 119) suggested that the form evolved from earlier cylinder seals that, although retaining their domed back, were given a flat base enabling them to be used as stamps. This direct development has been rejected by Wiese $(1996,56)$ who noted that the type of decoration on the two types of seals is completely different, one being a continuous pattern, the other a single stamped pattern.

The design on the bottom is similar to that found on button seals from Mahasna dated to Dynasty 6 and later (Garstang 1903, 33, pl. 39), while others have commented that the meander pattern is characteristic of First Intermediate Period seals. ${ }^{3}$ Brunton $(1927,56)$ and Slater $(1974,251)$ noted that objects with the meander pattern are earlier than those with spiral/scroll patterns (for example, PAHMA 6-14374) that occur as early as Dynasty 9. Newberry $(1906,59)$ noted that these hemi-cylinder seals almost always have geometric patterns on their bottom. ${ }^{4}$

According to Newberry $(1906,61)$, these hemi-cylinders are always glazed in either blue or green.

3 See Haynes and Markowitz (1991, nos. 7-8), with reference to Garstang (1903, pl. 39).

4 See other examples in Wiese (1996, pls. 59-6o). 
This is such a small object that it appears to be an amulet or a purely decorative object, like a bead rather than being intended as a functional stamp seal.

Compare to Garstang 1903, pl. 39; Petrie 1925, pl. 4 (no. 249) from Diospolis Parva; Reisner 1932, 114 (fig. 49.3-4, 8-11), 115 (g), for examples of a series of very similar small objects with "meandering line patterns," especially fig. 49.5 from N 2034 at Naga ed-Deir; Hayes 1953, 143 (fig. 85, lower right), on a First Intermediate Period seal; Ward 1978, 47-48; Haynes and Markowitz 1991, no. 4 with a maze/labyrinth pattern and an unusual back in the form of two scribes, seated back to back, dated to the First Intermediate Period.

Published: Reisner 1932, 114 (fig. 49.5); Wiese 1996, pl. 6o (no. 1227), although the floral-like design on the top is incorrectly shown as a crosshatched pattern. Wiese, who noted erroneously that the location of this seal is "unbekannt" and so did not have access to it, has, for an unstated reason, turned his drawing of the base go degrees clockwise and the top 180 degrees from Reisner's drawing.
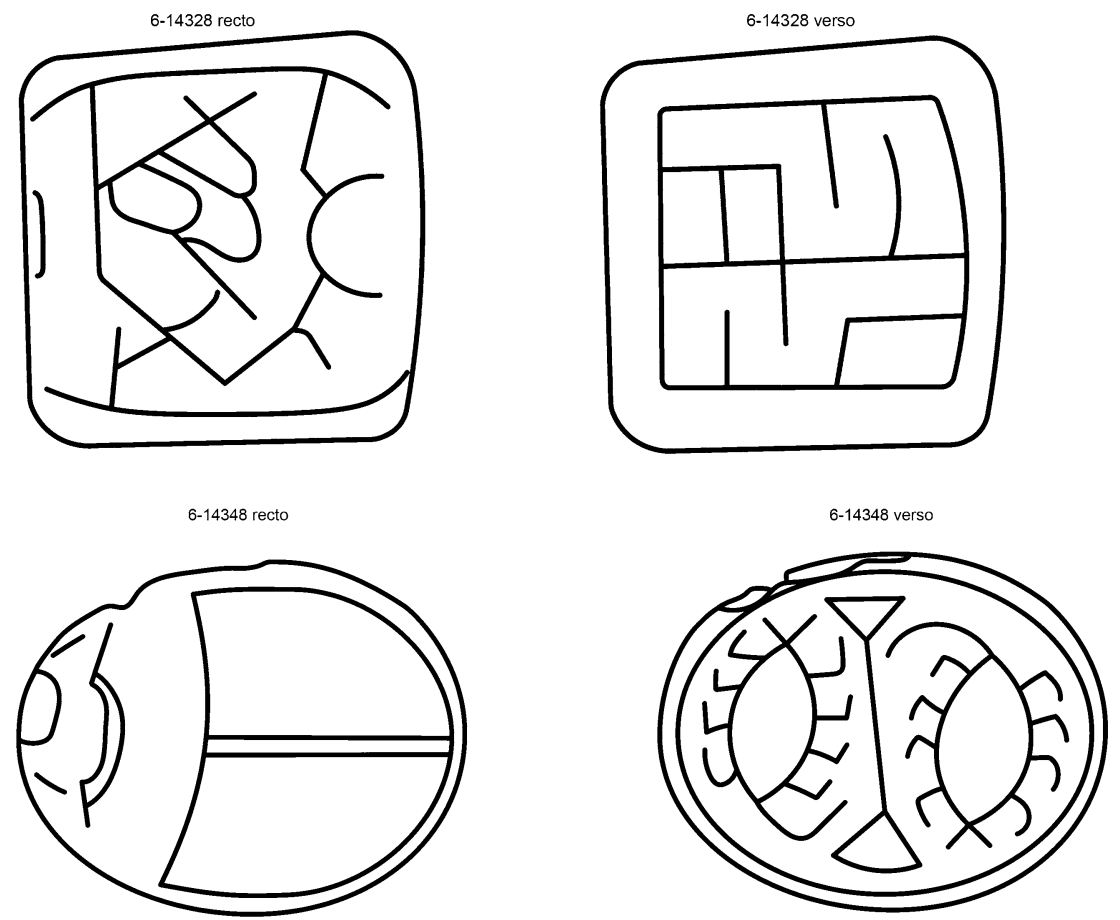

FIGURE 4.2 (1) Hemi-cylinder seal 6-14328. (2) Scarab 6-14348. (3) Scaraboid 6-14363.

(4) Scarab 6-14374. (5) Scarab 6-14383. (6) Reconstruction of cylinder seal with cross-hatch pattern and plain borders. Drawn after impression on 6-14447A.

(7) Round seal impression. Drawn after impression on 6-14447A. Not to scale. DRAWINGS BY V. DAVIES 

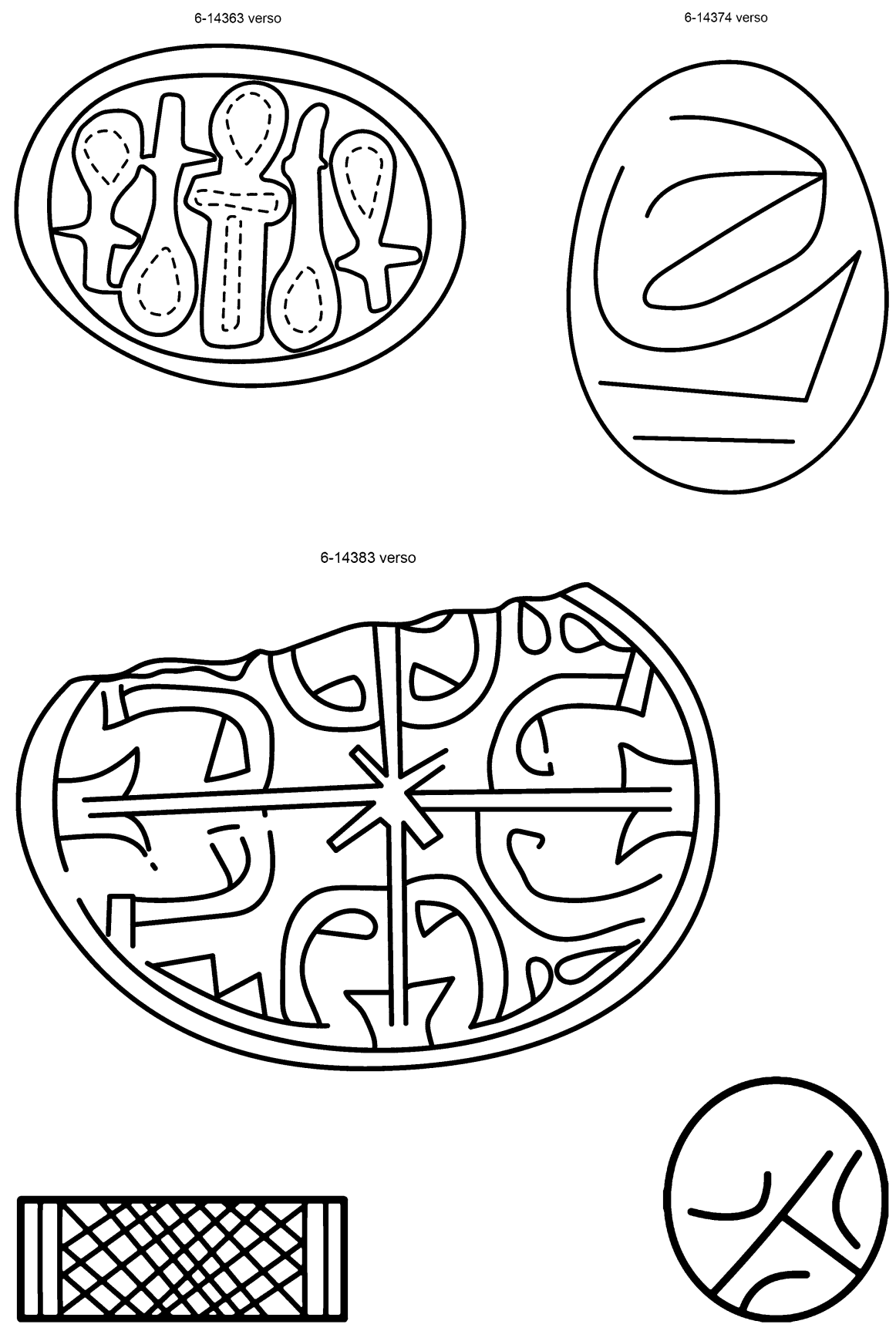
N 2048 Map B3

In radim, scarab (see drawing) (PAнмA 6-14348) (See note, below.)

(1) РАнма 6-14348 Scarab (Figs. 4.1, 4.2)

Material: Faience?

Measurements: L $1.47 \times \mathrm{W} 1.11 \times \mathrm{D} 0.73 \mathrm{~cm}$.

Weight: $1.0 \mathrm{~g}$.

Color: Blue-green.

Date: First Intermediate Period, Dynasties 8-9.

Scarab with good detail on the back. Double lines divide the elytra and a single curved line delimits the elytra from the prothorax. The head is broad and has a ruffled clypeus. The body sits atop tall legs, and the material has been carved out between the legs. The front and middle legs meet very far forward where the prothorax meets the head. The legs are on a tall platform.

The base of the scarab has two scorpions tête-bêche with a flower with buds at each end separating them. The scorpions are executed in a very linear fashion that Ward $(1978,51)$ suggests is "characteristic of the First Intermediate Period." The design is enclosed a single line frame. There are remains of very bright blue-green glaze on the elytra and in the incisions on the base. The piercing is very straight and regular.

Note on provenience: There is some doubt about from which tomb this was recovered. The Hearst Museum database records this from N 2051, but the original excavator's notes assign it to the radim of $\mathrm{N} 2048$.

The well-defined anatomy of the legs suggests that this is of a slightly later date than scarabs on a platform such as PAHMA 6-14374.

The design of animals, such as crocodiles and lizards, in a tête-bêche arrangement appears "with some frequency at this early date" (i.e., First Intermediate Period) (Haynes and Markowitz 1991, no. 5).

Double lines dividing the elytra and a single curved line that delimits the elytra from the prothorax are characteristic of Ward's Type II $(1978,29)$. The pattern of the legs is not included in Ward's typology $(1978,31)$ that shows the legs meeting where the prothorax (pronotum) and elytra join.

Compare to: Newberry 1906, pl. 42 (no. 31); Petrie 1925, pl. 14 (no. 930); Brunton 1927, pl. 33 (no. 168) also with naturalistically carved legs, dated to Dynasties 8-9; Haynes and Markowitz 1991, no. 5 for two crocodiles tête-bêche 
on the base of a design amulet. See also Newberry 1907, 88, pl.15 (no. 36349) with three scorpions in a much more naturalistic depiction, dated to Thutmose III. Not published.

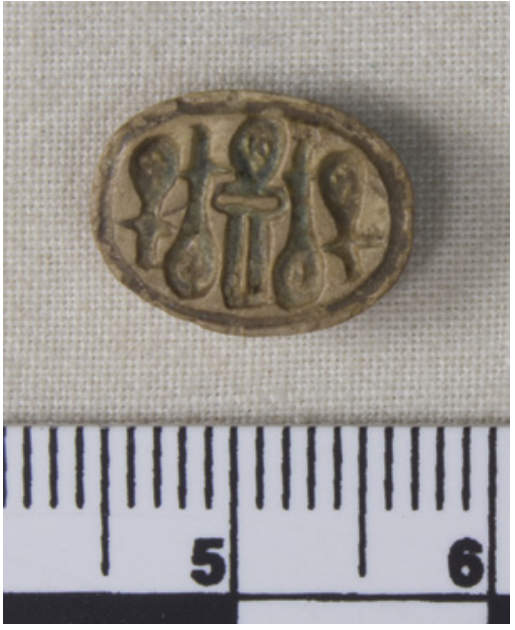

FIGURE 4.3

Scarab 6-14363 (N 2017) (See also NED-C-8567)

N 2071 Map B4; type rock-cut chamber with sloping entrance; photos C 8074, C 8567, A 8267, A 8268, B 825 o

(a) Body of a child. Round neck, a small scaraboid (iv) (PAHMA 6-14372; p. 308n1). Below, a second layer of burials. By neck of (e), 1 glaze scaraboid (xi) (PAHMA 6-14363).

(1) PAHMA 6-14363 Scaraboid (Figs. 4.2, 4.3)

Material: Glazed steatite (?).

Measurements: L $1.20 \times \mathrm{W} 0.915 \times \mathrm{D} 0.35 \mathrm{~cm}$.

Weight: $0.6 \mathrm{~g}$.

Color: Brown with traces of blue-green glaze.

Date: First Intermediate Period.

Oval scaraboid with a very faint line around the base (visible on one side only). Part of the back is worn away by the abrasion of the string on which it was strung. No glaze is preserved on the top, but blue green glaze remains in the hieroglyphs on the base.

The decoration on the base is enclosed in an oval frame. The design consists of a central stylized ankh flanked by what appear to be nefer signs. A difficulty with their interpretation is the round base of the signs may be intended to be a loop as indicated by a raised center area. If so, they were perhaps intended to be additional ankh signs. 
The faint line visible on one side of the back, near the base, makes it difficult to determine if this was supposed to be a cowroid.

Note on provenience: This came from a tomb of a child with 29 other objects, including scarab PAHMA 6-14374.

Stylistically, this scarab is like a First Intermediate Period example from Matmar (Brunton 1948, pl. 33 (no. 87)), with bold signs that leave a considerable part of the background open. The vertical line that bisects the "stem" of the ankh and the broad transverse arms are known from colossal statues of Senwosret I at Karnak. ${ }^{5}$ See Ward $\left(1978,55^{-5} 6\right)$ for comments about variations in the form of the ankh on pre-Dynasty 12 scarabs.

Compare to Newberry 1907, 228-229, pl. 11 (nos. 36910, 36911) for the same signs (dated to the Hyksos, and the First Intermediate Period or Hyksos, respectively), but arranged differently and with the addition of an $r$ hieroglyph. See also Newberry 1907, 208, 225, 270, pl. 16 (nos. 36827, 36897, 37078), all with single ankh and nefer, dated to Dynasty 18.

Not published.

(2) PAHMA 6-14374Scarab (Figs. 4.1, 4.2)

Material: Glazed material.

Measurements: L $1.10 \times \mathrm{W} 0.705 \times \mathrm{D} 0.53 \mathrm{~cm}$.

Weight: 0.5 g.

Color: Brown with traces of green glaze.

Date: First Intermediate Period.

Scarab with very little detail on the back. The legs are not shown. A line divides the scarab from the base, creating a high oval plate.

The decoration on the base is difficult to make out, but Reisner $(1932,116)$ categorized it as a scroll pattern. Ward (1978, 102, pl. II (no. 40)) classified this scarab as design class 1A (maze) from his Period Two (early Dynasties 9-10 "and the first half of the contemporary local Eleventh Dynasty").

Green glaze is preserved in spots on the back and in the incisions on the base.

Note on provenience: This came from a rich tomb of a child with 29 other objects, including scarab PAHMA 6-14363 and a string of green faience beads around the child's neck.

5 Oppenheim et al. 2015, 70 (fig. 55). 
Note on date: Brunton $(1927,56)$ and Slater $(1974,251)$ state that scarabs without legs (like this example) are earlier that those with more naturalistic legs. Reisner $(1932,110)$ dates this type of scarab that sits on a high oval plate to the early Middle Kingdom, while Ward $(1978,10)$, places them in the First Intermediate Period.

Compare to: Garstang 1903, pl. 39 (no. 343, top left of plate).

Published: Reisner 1932, 115, fig. 50.13, 116(i) as an "early scarab seal;" Ward 1978, 10, 102, pl. II (no. 40).

N 2075 Map A4; type vi d; photo C 8074, B 8248

[ed.: According to Hearst Museum records, PAHмA 6-14383 (scarab) is from this burial.]

(1) PAHмA 6-14383 Scarab (Figs. 4.1, 4.2)

Material: Steatite.

Measurements: L $2.71 \times$ D $1.155 \mathrm{~cm}$.

Weight: $7.1 \mathrm{~g}$.

Color: Brown.

Date: Late First Intermediate Period?

Scarab, with part of the left side broken and lost. Additional thin pieces of the steatite have sheared off, leaving little detail on the back other than lines that represent the division of the elytra and the division of the prothorax from the elytra and the head. The legs are indicated by a double line that encircles the scarab. There is no definition of the anatomy of the legs, similar to Ward's pattern "o" $(1978,31)$. The head is not well enough preserved to categorize it.

The base is decorated with a sm? t3wy design, the sm? sign being shown four times, its base at the outer edge of the scarab. The crossbar at the top of each sign is intertwined to make an X pattern. Floral emblems representing lily and papyrus cross the neck of the $s m$ ' signs. Small double triangles represent the marsh in which the plants grow. A single line frames the decoration.

Brown glaze remains in the hieroglyphs on the base and also in the lines that define the back. The steatite is very friable.

Note on provenience: This scarab was from a very rich tomb that contained cosmetic vessels, three mirror disks (PAHMA 6-14393, PAHMA 6-14394, PAHMA 6-14395), and many conical beads and shells.

Ward $(1978,72-73)$ states that on pre-Dynasty 12 scarabs, the single $s m$ 3 sign appears alone, while in Dynasty 12 and afterward, the $s m$ 3 is "doubled or 
appears in combination with other signs." The pattern of four intertwined sm3 signs on this scarab suggests that Ward's comment is not accurate because this scarab surely predates Dynasty 12 . So too, Ward's conclusion that the base of floral elements are pointed or curved before Dynasty 12 is not born out by this scarab, which has a thick, flat base that, according to Ward (1978, 74), is post-Dynasty 12. For scarabs with two sm3 signs, see Petrie (1925, pl. 10 (no. $379(?), 388)$ ).

Comparable examples date to later periods. See Haynes and Markowitz (1991, nos. 37-38) with same sm3 t3wy pattern, dated to the early Second Intermediate Period, and Newberry (1906, pl. 20 (nos. 20-24)) with bases that incorporate the sm? t3wy design, dated to "Twelfth to Eighteenth Dynasties."

Not published.

\section{N 2449 Map B4}

Approx. 210 deep. 80 high. Female? On breast, at X, a bronze button (i) with loop back, covered with cloth on both sides (PAHMA 6-14539).

(1) PAHMA 6-14539 Button Seal

Material: Copper alloy (?), textile.

Measurements: L $2.4 \times \mathrm{W} 1.2 \times \mathrm{D} 0.3 \mathrm{~cm}$.

Color: Bright green corrosion, beige textile.

Date: First Intermediate Period, Dynasties 7-8.

Round seal with a thin loop handle. The face of the seal is badly corroded, and any original design (if it was even decorated) cannot not be made out. Textile adheres to part of the back and one edge of the loop handle.

Buttons of steatite, limestone, rock crystal, bone, alabaster, and pottery from this period are known (Petrie 1925, 1-2; Hayes 1953, 142), but examples in metal seem to be very rare. However, copper alloy objects (amulets, beads, a mirror disk, and vessels) were recovered from other, earlier cemeteries at Naga edDeir (N 500-9oo in Reisner 1932, index). Brunton $(1927,57)$ noted that metal was only rarely used for seal amulets.

Button seals appear in Dynasty 5, becoming more common in Dynasty 6, and they continue in use through Dynasty $11 .{ }^{6}$ Brunton $(1927,57)$ noted that round buttons with a shank most commonly date to Dynasties $7-8$.

6 Oppenheim et al. 2015, 484. Hayes $(1953,141)$ says buttons and stamps appear Dynasty 6 , as does Newberry $\left(1906,57^{-58)}\right.$. 
It is debated whether these were functional seals or amulets, or if they served a combination of these functions (Petrie 1925, 1).

If this tomb indeed belonged to a woman, it would reinforce the pattern seen at other contemporary sites where most seal amulets were placed in the tombs of women (summarized by Brunton 1948, 50). Slater $\left(1974,25^{\circ}\right.$ ) noted that seals (presumably referring to stamp seals) were generally not common at Naga ed-Deir.

Not published.

Seal Impressions and Knotted Cords from Tomb $\mathrm{N} 2232$

\subsection{Description}

Four groups of cords knotted along their length with clay sealings attached to them were recovered from $\mathrm{N} \mathrm{2232.} \mathrm{The} \mathrm{tomb} \mathrm{card} \mathrm{describes} \mathrm{the} \mathrm{material}$ as "At side of coffin remains of basket work, with clay sealings attached. May have originally enclosed coffin." ${ }^{7}$ However, closer examination of the material makes this interpretation unlikely. The strands of knotted cord are not attached to each other to make a network as would be expected for a basket or a sling (Figs. 4.4, 4.5). ${ }^{8}$ On PAH MA 6-14448B, the lengths of knotted cord appear to have been folded back and forth along their length to form a short hank and then tied with a piece of the cord and sealed with a clay bulla. The breakage of the strands and the sealings make it impossible to determine if the strands consisted of a few very long knotted cords that were gathered and sealed, or multiple separate pieces that were likewise folded back along their length, tied and sealed. ${ }^{9}$

Each group now presents itself as a dense nest of knotted cords. The material was given four different numbers (PAHMA 6-14447, PAHMA 6-14448,

7 The description continues "Sealings were only at top of coffin on N side; no trace underneath. Each was marked with 2 round seals." Although a little vague, I take it to mean that the entire group of cords with their seals were found as a group on top of the coffin.

8 For examples of roughly contemporary rope slings from the tomb of Ipy at Thebes, see Winlock (1942, 56, pl. 18 (top)), Hayes (1953, 193, 262) (both Dynasty 12 from Lisht, the latter with reference to "knotted slings of rope" of much larger scale), and Hayes $(1953,292)$ for "knotted rope pot slings" from Deir el-Bahri dated to Dynasties 11-12. I thank Peter F. Dorman for the information about the jar sling from the tomb of Hatnofer (Dynasty 18).

9 However, considering the number of knots and the difficulty of making numerous small knots in a very long length of cord, shorter lengths would be more manageable, regardless of their function. 


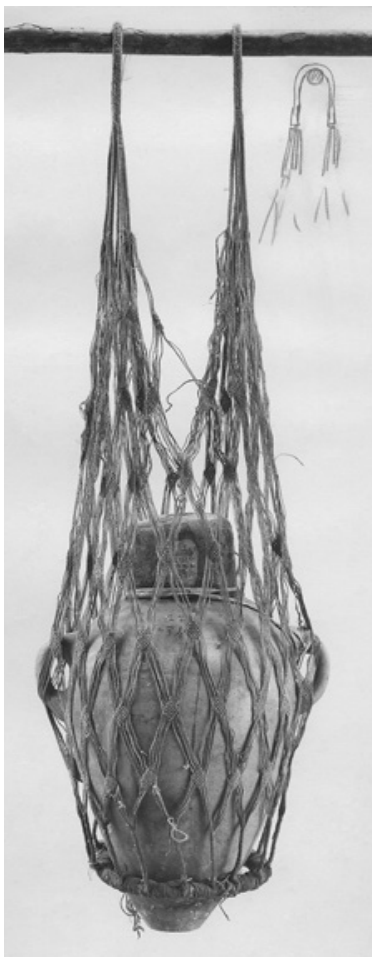

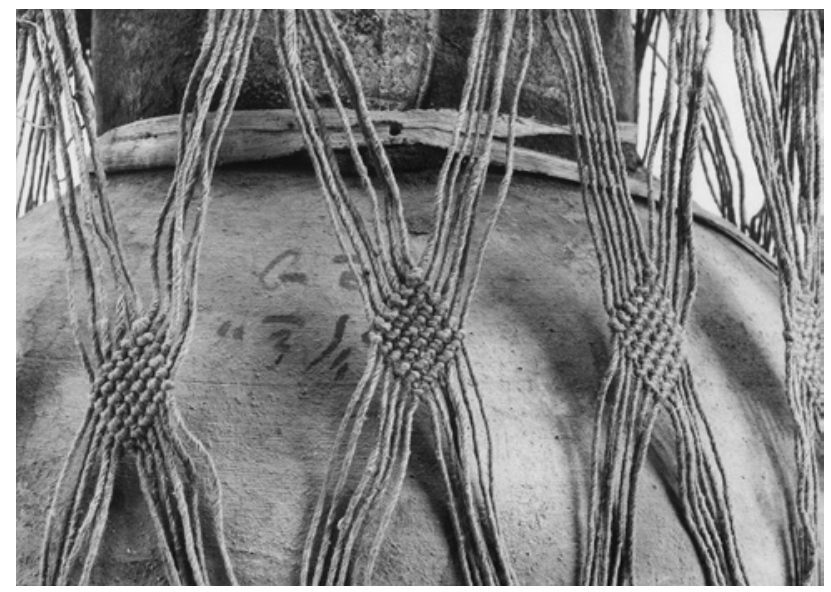

FIGURE 4.5 Detail of knots on jar sling from the tomb of Hatnofer. Photo MC16 188 COURTESY OF THE METROPOLITAN MUSEUM OF ART

FIGURE 4.4

Jar sling made of knotted fibers. Tomb of Hatnofer, Thebes, Dynasty 18 (ca. 1473-1458 BC). Photo MC16 187 COURTESY OF THE METROPOLITAN MUSEUM OF ART

PAHMA 6-14449, PAHMA 6-14450). ${ }^{10}$ PAHMA 6-14448B and perhaps PAHMA 6-1445 $\mathrm{OA}$ are separate objects (bundles of cord), but it is not clear if the rest of the material is part of those two, parts of each other, or part of other individual pieces, hence how many discreet objects are represented.1

Both the diameter of the cord and the length between the knots varies slightly. All the cords seem to be made of double strands. The knots appear to be overhand knots. Willeke Wendrich identified the material as being composed of sZ2 string made of halfa grass (probably either Desmostachya bipinnata or Imperata cylindrica) with repeated S-overhand knots. ${ }^{12}$ She commented, "Most grass string is made in the opposite direction, two z-spun yarns, that are S plied

10 Because most of the groups contained multiple sealings, I gave them (and their attached cords) alphabetic designations to differentiate the sealings within each registered group.

11 Especially looking at PAHMA 6-14448B on which the cords appear to have been folded back and forth on each other and tied to create a packet. My best guess is that there are least two discreet objects.

Personal communication from Willeke Wendrich. 
$(\mathrm{zS} 2)$. In this case the spin/ply direction is s-spun and Z-plied, which is much less common." The fiber now is a uniform dark brown color and is very brittle.

\subsection{The Sealings}

Seven clay sealing (and fragments of sealings) are preserved among the samples. All are still attached to the segments of knotted cord. When the back of a sealing is exposed, there are very clear impressions of the cords and knots. ${ }^{13}$

Each sealing captured multiple stands of cord. Most have areas that have been flattened or deformed by the pressure of the seal as it was applied.

The consistency of the clay used for the sealings is generally fine-textured and uniform, although some of the bullae (PAHMA 6-14447A, B, PAH MA 6-14448A) have pits and cracks in their surface, perhaps from air pockets in the clay. PAHMA 6-14448B in particular has numerous surface cracks, perhaps from the clay drying unevenly. All the sealings with the exception of PAHMA 6-14449 are a uniform brown color, while PAHMA 6-14449 is a lighter ashy gray tone.

\subsubsection{The Seal Impressions}

The sealings were covered with impressions made by two different seals. The most frequently occurring impression is a cross-hatch or basket pattern with a plain border (Fig. 4.2, 6) very much like the pattern on a cylinder seal recovered from $\mathrm{N}_{5}{ }^{\circ}$ at Naga ed-Deir. ${ }^{14}$ On impressions in PAHMA 6-14448B and PAHMA 6-1445oB, it appears to be more oval but this probably due to the side of the cylinder being pressed into the clay rather than rolled over it. The clearest impressions of this seal are on PAHMA 6-14447A and PAHMA 6-1445oB. On PAHMA 6-1445oB, it looks like the seal was applied from two different directions. The impressions made by this seal are extremely crisp suggesting that the seal itself was made of a hard stone and was of fine quality. ${ }^{15}$ The other impression was made by a round button seal whose face has a T-like shape in the middle with indistinct patterns around it (Fig. 4.2, 7).

None of the impressions of this seal from the $\mathrm{N} 2000$ cemetery are complete and totally clear, but the design strongly resembles two other button-seals

\footnotetext{
13 See especially ранма 6-14449.

14 Reisner 1932, 112, fig. 47.1 from N 505(1), and 111, described as a "cylinder-seal of bone." The cross-hatch pattern (or as Reisner terms it, a "lattice") also appears on a round button seal from N 505 (Reisner 1932, 111 (2), fig. 47.2), and he cites another (113 (I) a, fig. 48.1) in "Newberry l.c."

15 Nadine Moeller (personal communication) noted that such fine quality seals at Edfu and Dendera are associated with higher levels of the administration and that they are often made of luxury materials like amethyst.
} 
from Mahasna. ${ }^{16}$ The best-preserved examples of this seal impression are on PAHMA 6-14447A and PAHMA 6-14448A where it is clearly made with a round button seal. The impressions made by this seal are not as fine in detail suggesting that it was made of a material like faience rather than stone.

The cross-hatch pattern made by the cylinder is represented twice as frequently as the round $\mathrm{T}$ seal. Most of the seal fragments (PAHMA 6-14447A and B, PAHMA 6-14448A, PAHMA 6-14449, PAHMA 6-1445०B) have two examples of the cross-hatch and a single round impression, whereas PAHMA 6-14448B appears to have perhaps 3 cross-hatches and one T circle. PAHMA 6-1555०A has two cross-hatches and no circle. On PAHMA 6-14448A and B, the round impression appears on top of the cross-hatch as a counterseal.

\subsubsection{Other Material}

Very small shells, perhaps Phasianella solida $\left(3^{-21} \mathrm{~mm}\right)$, or Littoraria intermedia (actual size $8.5^{-22} \mathrm{~mm}$ ) are embedded into the strands of the fiber of PAH MA 6-14448B. Shells are also preserved in the modern storage bag registered as PAHMA 6-14448C that contains bits of cord, knots, and very small fragments of stone.

\section{$3 \quad$ Sealings and Cords Catalogue}

Explanation of the Sealings and Cords Catalogue:

The finds' description of context below is taken from the Catalogue of Tombs. The photograph numbers reflect the original excavator's numbering system.

Museum Registration: Name and museum number of object.

Material: Clay, cord, fiber.

Measurements: Length, width, thickness.

16 Reisner 1932, 114, fig. 48.27, 118 “3. Obscure Designs (a);” Garstang 1903, pl. 39, no. 417 (top photo, left middle of the image). 


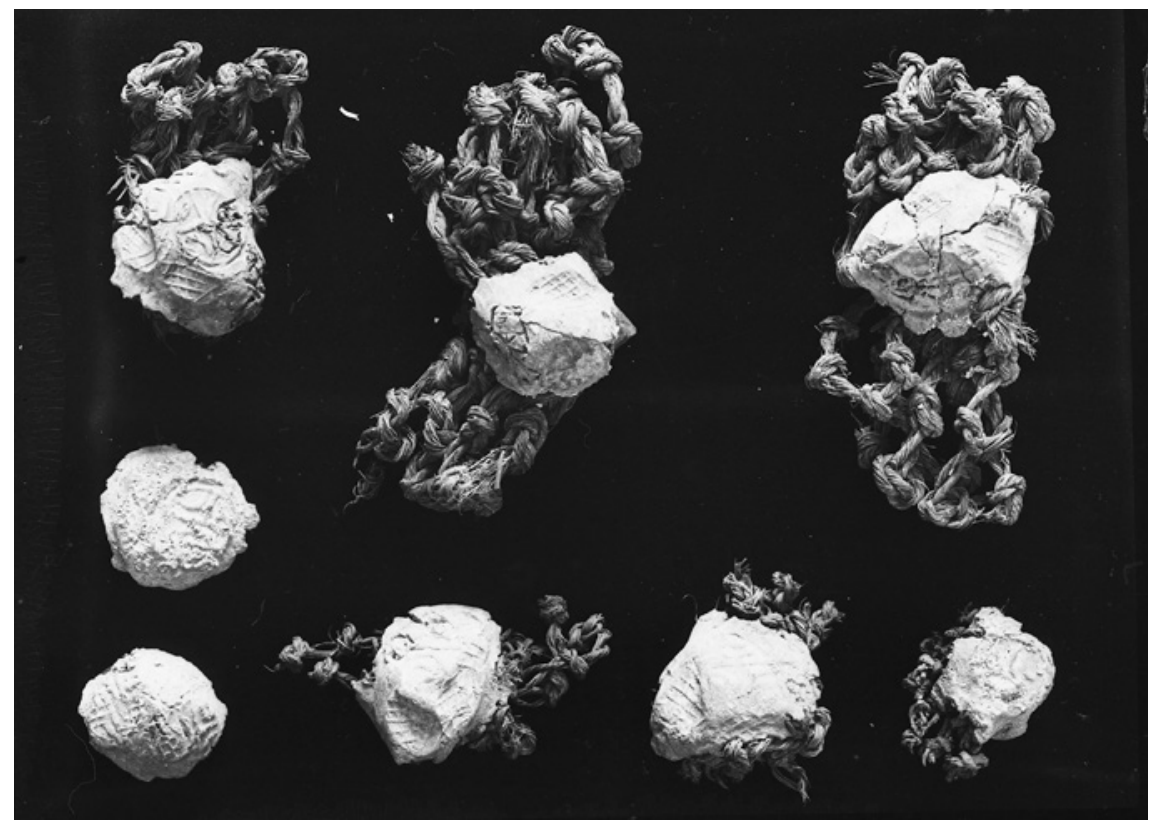

FIGURE 4.6 L-R (top): 6-14448, 6-1445o, 6-14447; (middle): ?; (bottom): 6-14447?, 6-14447?, 6-1445o, 6-14449? (N 2232) (NED-C-859o)

\section{N 2232 Map E4; photos C 7468, C 8589 (Fig. 4.6)}

At side of coffin, remains of basket work with clay sealings attached (PAHMA 6-14447, PAHMA 6-14448, PAH MA 6-14449, PAHMA 6-14450). May have originally enclosed coffin. Body was apparently untouched, but coffin had no lid remaining. Sealings were only at top of coffin on north side: no trace underneath. Each was marked with 2 round seals.

(1) PAнма 6-14447A Sealing and knotted cord Material: Clay, fiber.

Measurements of sealing: $32 \times 26 \mathrm{~mm}$; thickness: $21 \mathrm{~mm}$.

Depending on the side viewed, the sealing can appear to be nearly round. It is of uniform brown color. The pressure of the seals has flattened the sides into different facets with ridges of clay between them. It is sealed with two very crisp cross-hatch seal impressions and one T-shaped that covers most of one side of the sealing. The latter is among the best and clearest examples of the sealing, although the clarity of the impression is obscured by pits in the surface of the clay. 
The sealing is now detached from the lengths of cord, but the sealing captured several strands whose ends emerge from the clay. The cord is slightly thinner in diameter than others in the find, being more similar to PAHMA 6-1446oB. The knots on one sample of this group were placed intervals of approximately 2,4 , and $11 \mathrm{~mm}$.

Not published.

(2) PAнma 6-14447B Sealing and knotted cord Material: Clay, fiber.

Measurements of sealing: $30 \times 28 \mathrm{~mm}$; thickness $17 \mathrm{~mm}$.

Depending on the side viewed, the bulla can appear to be nearly round, while from another angle it is a rectangle. It is of uniform brown color and is fine textured clay. It is broken into several pieces most of which still adhere to the cords.

Most of the surface is covered with seal impressions. The two cross-hatched seals are deeply impressed into the clay. The T-shape is impressed over one of the cross-hatched seals. The surface of the impression is marked by pits in the clay.

The sealing is attached to a gathering of knotted cords.

Not published.

(3) PAHмa 6-14448A Sealing and knotted cord Material: Clay, fiber.

Measurements of sealing: $31 \times 37 \mathrm{~mm}$; thickness: $23 \mathrm{~mm}$.

The sealing is irregular shaped, roughly a sphere and of uniform brown color. It bears two examples of the cross-hatch seal, one on a concave surface where the clay was deformed by the pressure of the seal. Unlike other impressions that seem to have been made with a cylinder seal, here it appears to be an oval, although that is probably because the seal was simply pressed against the damp clay rather than rolled. There is a very clear impression of the round T-shaped seal. The pressure of the seal made a regular flat facet in the clay. The T-seal was applied over the cross-hatch impression. It is marred by small cracks and pits probably caused by the clay drying. The sealing has many small cutlike incisions on the sides from the fiber of the cords.

The sealing is detached from lengths of cord although numerous short sections with knots are embedded in it.

Not published. 
(4) PAHMA 6-14448B Sealing and knotted cord

Material: Clay, fiber.

Measurements of sealing: $37 \times 36 \mathrm{~mm} \cdot{ }^{17}$

The sealing is an irregular oval shape and of uniform brown color. It is cracked into pieces, but the fragments still adhere to the knotted cords. It is medium brown in color. The bulla has numerous cracks that expose the sealed cord.

The sealing is impressed with three (?) of the cross-hatched impressions, each of which was applied from different angles. There is one very clear T impression that overlaps a cross-hatched impression.

The sealing is attached to a large amount of knotted cord measuring approximately $8.4 \times 3.4 \mathrm{~mm}$. The cord is knotted at close intervals that vary between 5 and $10 \mathrm{~mm}$. The lengths of the knotted cord were folded back and forth against itself to make a bundle. One loop where the cord has been reversed is preserved. Other ends, which could have been places where the cord was probably turned back on itself, are now broken. The bundle is tied across its center with cord that was twisted around it three (?) times, two of the encircling cords close together, the third further away. The cord used to tie the bundle appears to be of similar construction to the bundle itself, but the two ties close together appear to be less tightly twisted. Although the tie cords have knots, on the two ties closest together, the knots are not visible on the cord to the left, although they are visible on the one to the right. The third tie, further to the right, looks similar to the cords in the bundle in texture and the frequency of knots.

Fragments of small shells are embedded in the cords.

Not published.

(5) PAH MA 6-14448C Sample of cord, shells, and fragment of stone in a plastic bag

The shells may be Phasianella solida $\left(3^{-21} \mathrm{~mm}\right)$ or Littoraria intermedia (size $8.5^{-22} \mathrm{~mm}$ ). The best-preserved shell is $11 \mathrm{~mm}$ in length. See Reisner $(1932,121 \mathrm{ff})$. for the presence of what he identified as Nerita shells in tombs in the $\mathrm{N}_{5}$ oo-900 cemeteries.

Not published.

(6) PAнмA 6-14449 Sealing and knotted cord with multiple small indistinct fragments of other sealings with seal impressions and fragments of knotted cord

17 The way that the sealing is embedded in the cord makes it impossible to measure its thickness. 


\section{Material: Clay, fiber.}

Measurements of sealing: $31 \times 19 \mathrm{~mm}$; thickness $11 \mathrm{~mm}$.

The sealing is a flattened sphere of which only half is preserved. The clay is much lighter ashy gray in color than any of the other examples in the group. It is impressed with two cross-hatched sealings and one T.

The reverse bears impressions from the cord that it originally captured. The cord is knotted at intervals ranging from $6.5^{-11} \mathrm{~mm}$.

Not published.

(7) PAHMA 6-1455०A Sealing with knotted cord Material: Clay, fiber.

Measurements of sealing: $31 \times 30 \mathrm{~mm}$; thickness approximately $24 \mathrm{~mm}$.

The sealing is an irregular sphere and is of uniform brown color. It has two impressions of the cross-hatched seal. One is pressed into the clay producing a concave cavity that is diagnostic of a cylinder seal being pressed (rather than rolled) in the clay. A fingerprint is preserved in the clay.

The sealing is wadded around a capture of knotted cord. From the back, it is clear that the cord has been looped back on itself and then sealed, so it is not several separate strands. It appears that there are two different types of cord, one of larger diameter, the other of smaller diameter. The knots that could be measured occur at about $7 \mathrm{~mm}$ intervals.

Not published.

(8) PAHMA 6-1445oB Sealing with knotted cord Material: Clay, fiber.

Measurements of sealing: $36 \times 34 \mathrm{~mm}$; thickness $22 \mathrm{~mm}$.

From the top, it is an irregular sphere of uniform brown color. It is impressed with two cross-hatch seals that appear to be rolled from different directions. There is a single $\mathrm{T}$ seal. From the underside (with the knot capture) the shape of the bulla is an elongated oval bisected by knotted cord. One side of the bottom surface has another cross-hatch seal impression, while the surface on the other side of the cord does not have any impressions.

The bulla is attached to short pieces of cord that appear to be of a lighter weight and have less twist that the other examples in the overall group. The difference in the appearance of the cord on this example is quite marked from PAHMA 6-14450A.

Not published. 
The most notable feature of this material is the value of the labor expended upon tying hundreds of small knots onto the double strands which themselves reflect considerable effort to manufacture. The resulting knotted cords were important enough that they, and perhaps more significantly their lengths, were preserved by gathering them and sealing them with clay bullae.

As stated, because the cords do not form a network, they appear to be individual strands of undetermined lengths that were gathered together and sealed.

Knotted cords suggest two very different purposes: magical/medical or record keeping. Several texts refer to tying knots in string or along lengths of linen to protect against sickness (Wendrich 2006, 251). Strings with lines of knots were thought to be a "barrier which evil forces cannot pass," or the knots had the power to keep good forces from escaping (Pinch 1994, 83; Wendrich 2006, $247,253)$. Linear knots could also function as a mnemonic device to record a requisite number of recitations of spells (Wendrich 2006, 253). Amulets in the form of knots are well known, such as the tyt, šn, ț (Wendrich 2006, 253-255; Andrews 1994, 44-45, 59, 86; 68, 76-77; 44).

The other purpose, as a recordkeeping device, seems more applicable to this material because of the presence of the sealings that suggest an administrative rather than a magical function. In this case, the knots in the strands might record specific distances and hence be related to measuring distances. ${ }^{18}$

Although no examples of knotted measuring cords are known to survive from antiquity (Clarke and Engelbach 1930, 65), they are shown on at least two New Kingdom statues, and at least eleven scenes in tombs show them in use, the knots "apparently indicating subdivisions, probably cubits" (Arnold 1991, 252). ${ }^{19}$ The measuring cords shown on statues have a "tying up cord" (Clarke and Engelbach 1930, 65; Roehrig 2005, 122-124), perhaps like the ties that secure bundle PAHMA 6-14448B.

There was a well-established tradition of placing models of tools and of entire workshops in tombs, especially in the Middle Kingdom (Winlock 1955; Freed et al. 2009). Hayes (1953, 288-289, fig. 189) noted "small carefully made models from burials of the Eleventh and Twelfth Dynasties at Thebes, Assyut, and el-Lisht," including a small tool chest from the tomb of Ankhef at Assyut

18 I thank Willeke Wendrich for suggesting this possible interpretation. They may be likened to the quipu of the Inca, which record specific numbers.

19 For statues, see that of Senenmut in Roehrig (2005, 122-124), and Penanhuret in Clarke and Engelbach (1930, 65, fig. 63). For the representation of surveying ropes in tombs, see Arnold (1991, 252n8), and Clarke and Engelbach (1930, 64-65). 
stocked with axes, adzes, and reamers. ${ }^{20}$ Tombs of the First Intermediate Period and Middle Kingdom are well known for collections of miniaturized pottery and tools, making it tempting to interpret the knotted cords from N 2322 as miniaturized copies of surveying tools. Although speculation, perhaps the owner of the tomb (assuming it was a man) was involved with measuring fields for taxation purposes. ${ }^{21}$

\section{Bibliography}

Andrews, C. 1994. Amulets of Ancient Egypt. London.

Arnold, Di. 1991. Building in Ancient Egypt. Oxford.

Brunton, G. 1927. Qau and Badari I. London.

Brunton, G. 1948. Matmar. British Museum Expedition to Middle Egypt 1929-1931. London.

Clarke, S. and R. Engelbach. 1930. Ancient Egyptian Construction and Architecture. Oxford.

Freed, R. E., L. M. Berman, D. M. Doxey, and N. S. Picardo. 2009. The Secrets of Tomb 10A: Egypt 2000 B.C. Boston.

Garstang, J. 1903. Mahasna and Bet Khallaf. Seventh Memoir. London.

Grajetzki, W. 2014. Tomb Treasures of the Late Middle Kingdom: The Archaeology of Female Burials. Philadelphia.

Hayes, W. C. 1953. The Scepter of Egypt. A Background for the Study of the Egyptian Antiquities in the Metropolitan Museum of Art, Part 1. From the Earliest Times to the End of the Middle Kingdom. New York.

Haynes, J. and Y. Markowitz. 1991. Scarabs and Design Amulets: A Glimpse of Ancient Egypt in Miniature. nfa Classical Auctions, December 11, 1991. New York.

Newberry, P. E. 1906. Egyptian antiquities, scarabs; an introduction to the study of Egyptian seals and signet rings. London.

Newberry, P. E. 1907. Catalogue Général des Antiquités Égyptiennes du Musée du Cairo, nos. 36001-37521: Scarab-shaped Seals. London.

Oppenheim, A., Do. Arnold, Di. Arnold, and K. Yamamoto, eds. 2015. Ancient Egypt Transformed: The Middle Kingdom. New York.

Petrie, W. M. F. 1925. Buttons and Design Scarabs. London.

$20 \quad$ Contra Grajetzki $(2014,12)$, who states "Egyptian burial equipment rarely contains objects related to the profession of the deceased ... The profession of the deceased is not visible in the tomb equipment."

21 Unfortunately, nothing is known about the owner of $\mathrm{N} 2232$. 
Reisner, G. A. 1932. A Provincial Cemetery of the Pyramid Age: Naga-ed-Dêr, Part III. University of California Publications, Egyptian Archaeology 6. Berkeley.

Roehrig, C. H., ed. 2005. Hatshepsut: From Queen to Pharaoh. New York.

Slater, R. A. 1974. "The Archaeology of Dendereh in the First Intermediate Period." PhD diss. University of Pennsylvania.

Ward, W. A. 1978. Studies on Scarab Seals I:Pre-12th Dynasty Scarab Amulets. Warminster. Wendrich, W. 20o6. "Entangled, Connected, or Protected? The Power of Knots and Knotting in Ancient Egypt." In Through a Glass Darkly: Magic, Dreams \& Prophecy in Ancient Egypt, edited by K. Szpakowska, 243-269. Swansea.

Wiese, A. B. 1996. Die Anfänge des ägyptischen Stempelsiegel-Amulette. ово, Series Archaeologica 12. Freiburg.

Winlock, H. E. 1942. Excavations at Deir el Bahri: 1911-1931. New York.

Winlock, H. E. 1955. Models of Daily Life in Ancient Egypt from the Tomb of Meket-Rè' at Thebes. New York. 